\title{
Immunohistochemical Expressions of Main PGE Biosynthesis-related Enzymes and PGE 2 Receptor in Rat Nephrogenesis
}

\author{
Emi Yamamotoํ, Takeshi Izawa1, Mitsuru Kuwamura1, and Jyoji Yamate \\ ${ }^{1}$ Laboratory of Veterinary Pathology, Life and Environmental Sciences, Osaka Prefecture University, Rinkuu Ourai \\ Kita 1-58, Izumisano, Osaka 598-8531, Japan
}

\begin{abstract}
Endogenous prostaglandin ( $\mathrm{PG}) \mathrm{E}_{2}$ plays important roles in renal homeostasis. Immunoexpressions of $\mathrm{PGE}_{2}$ biosynthesis-related enzymes, cyclooxygenase (COX)-2 and microsomal $\mathrm{PGE}_{2}$ synthetase (mPGES)-1 and EP4 (a PGE 2 receptor), were investigated in renal development. Kidney tissues were obtained from fetuses on gestation days 18 and 21 and neonates on days 1 to 18 . In fetuses and early neonates, the expressions of COX-2, mPGES-1 and EP4 were observed in developing renal tubules, indicating that $\mathrm{COX}-2$ and its product, $\mathrm{PGE}_{2}$, play important roles in blastemal cell-derived renal tubular development via EP4. Cyclin D1 expression was seen in both the nucleus and cytoplasm of the developing tubules. These findings differed from the decreased COX-2 expression and exclusive nuclear expression of cyclin D1 seen in abnormal epithelial regeneration of injured renal tubules in cisplatin-treated rats in our previous articles. Collectively, $\mathrm{PGE}_{2}$, induced by COX-2, regulates renal tubular epithelial formation via EP4. (DOI: 10.1293/tox.24.257; J Toxicol Pathol 2011; 24: 257-261)
\end{abstract}

Key words: rat, nephrogenesis, $\mathrm{PGE}_{2}, \mathrm{COX}-2$, EP4

Prostaglandin (PG), mainly $\mathrm{PGE}_{2}$, plays important roles in renal hemodynamics, renin release and salt and water homeostasis ${ }^{1,2}$. The $\mathrm{PGE}_{2}$ is synthesized from arachidonic acid; first, arachidonic acid is converted to an unstable intermediate $\mathrm{PGH}_{2}$ by cyclooxygenase (COX). $\mathrm{PGH}_{2}$ is converted to $\mathrm{PGE}_{2}$ by prostaglandin E synthase (PGES) 2,3 . COX consists of two isoforms, COX-1 and COX-2; COX-1 is constitutively expressed and responsible for basal PG production in relation to homeostasis, whereas COX-2 is an inducible form that may be primarily associated with inflammatory reaction ${ }^{4}$. In the kidney, however, the expressions of COX-1 and COX-2 are constitutively seen, and they play important roles in renal homeostasis ${ }^{5,6}$. The activity of $\mathrm{PGE}_{2}$ is mediated through four different receptor subtypes: EP1, EP2, EP3 and EP4. EP1 is associated with calcium mobilization, EP2 and EP4 are associated with stimulation of adenylate cyclase (AC) and EP3 is associated with inhibition of AC or with stimulation of phosphoinositol turnover'.

Received: 1 May 2011, Accepted: 10 June 2011

Mailing address: Jyoji Yamate, Laboratory of Veterinary Pathology, Life and Environmental Sciences, Osaka Prefecture University, Rinkuu Ourai Kita 1-58, Izumisano, Osaka 598-8531, Japan

TEL: 81-72-463-5334 FAX: 81-72-463-5346

E-mail: yamate@vet.osakafu-u.ac.jp

(C2011 The Japanese Society of Toxicologic Pathology

This is an open-access article distributed under the terms of the Creative Commons Attribution Non-Commercial No Derivatives (by-ncnd) License $<$ http://creativecommons.org/licenses/by-nc-nd/3.0/> .
Previously, we showed that endogenous $\mathrm{PGE}_{2}$ participated in abnormal regeneration of renal tubular epithelial cells after injury induced in rats by cisplatin (CDDP) exclusively through EP47. We considered that regeneration of renal tubules after injury recapitulates development processes in nephrogenesis ${ }^{8}$. To shed some light on renal tubular regeneration after CDDP injury, in the present study, we investigated expression patterns of main $\mathrm{PGE}_{2}$ biosynthesis-related enzymes, COX-2 and microsomal PGES (mPGES)-1, as well as EP4 in rat nephrogenesis. $\mathrm{PGE}_{2}$ may affect the $\mathrm{G}_{1}$ phase of the cell cycle of renal tubules through EP47. We also examined the expression of cyclin D1, a marker of the $\mathrm{G}_{1}$ phase in the cell cycle?

The following experiments conformed to our institutional guidelines for animal care. Pregnant female F344/ DuCrj rats were obtained from Charles River Laboratories Japan (Hino, Shiga, Japan). They were housed in an animal room controlled to $22 \pm 3{ }^{\circ} \mathrm{C}$ with a 12:12-h light-dark cycle and were allowed free access to a standard commercial diet (MF, Oriental Yeast Co., Ltd., Tokyo) and tap water. The day of birth was designated postnatal day 0 (P0). Animals were euthanized under deep anesthesia, and kidney tissues were obtained from fetuses on gestation days (GDs) 18 and 21, as well as neonates on days 1, 3, 6, 9, 1215 and 18 (at each examination point, at least three rat samples were used).

Kidneys were fixed in $10 \%$ neutral buffered formalin and periodate-lysine-paraformaldehyde (PLP) fixatives. Formalin-fixed samples were processed routinely and em- 


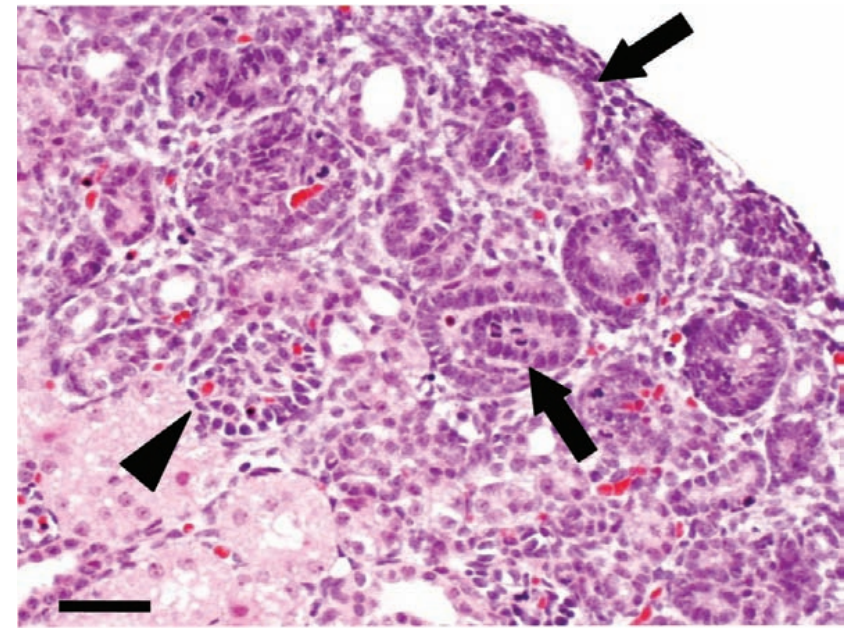

Fig. 1.

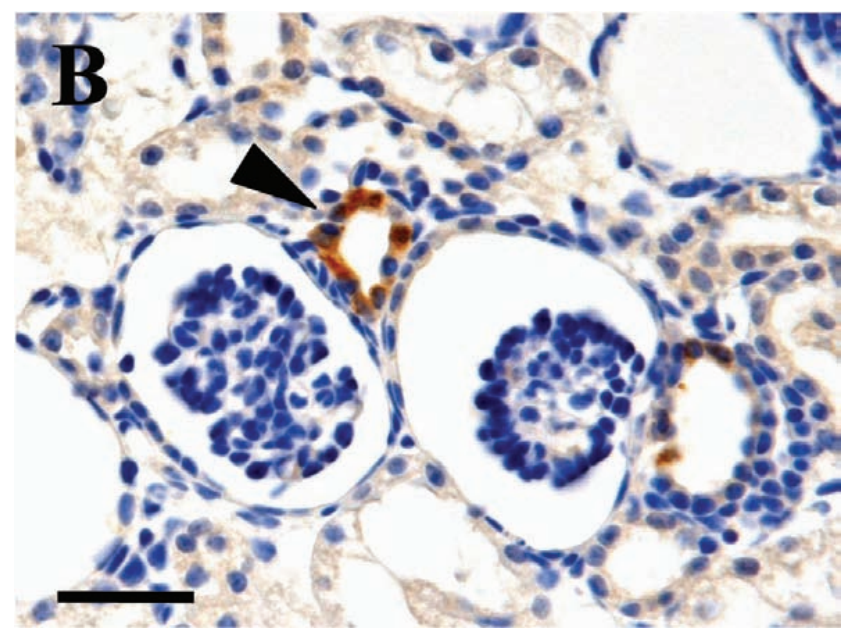

Fig. 2B.

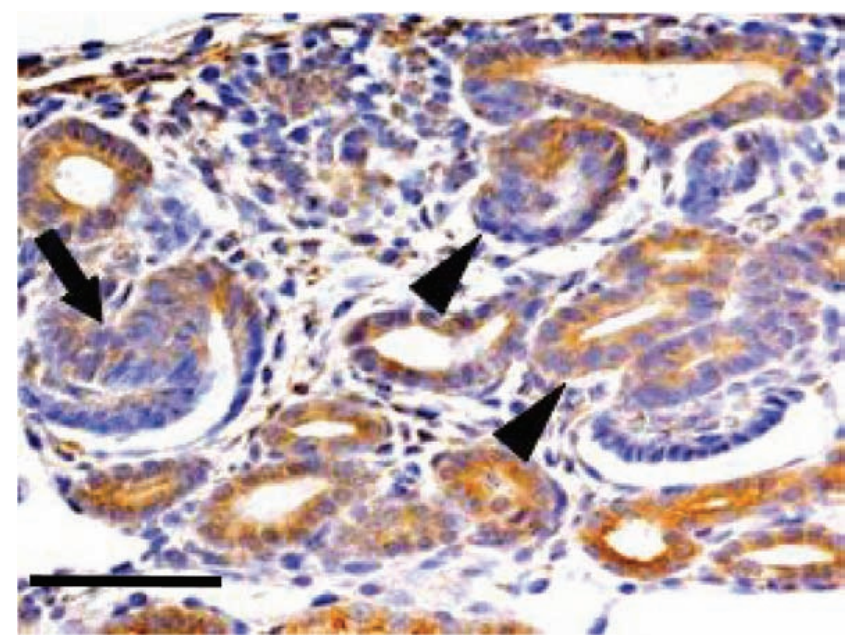

Fig. 4.

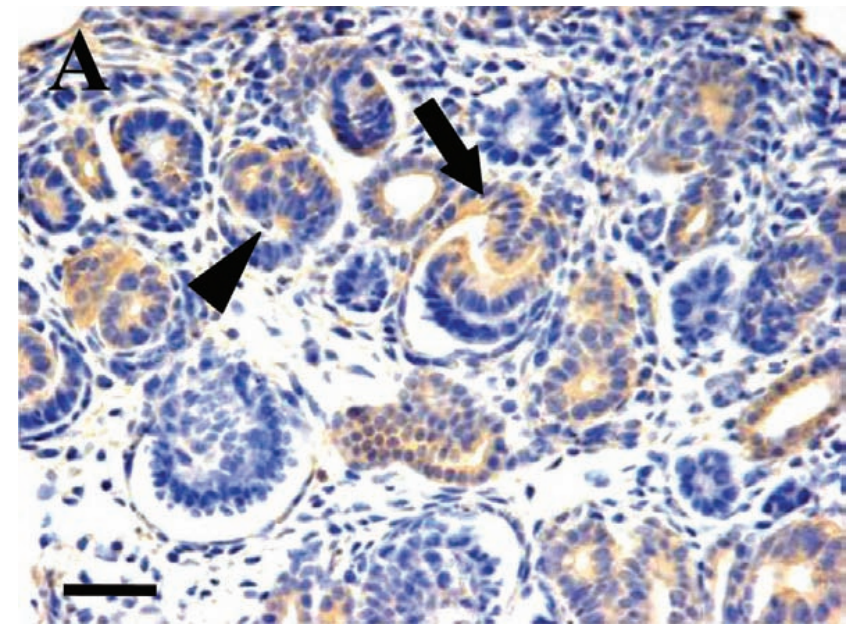

Fig. 2A.

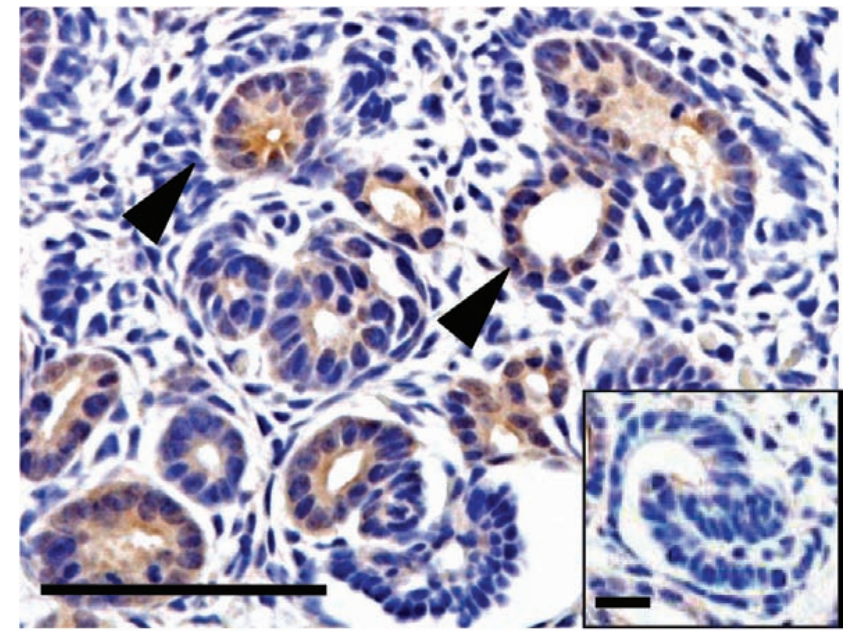

Fig. 3.

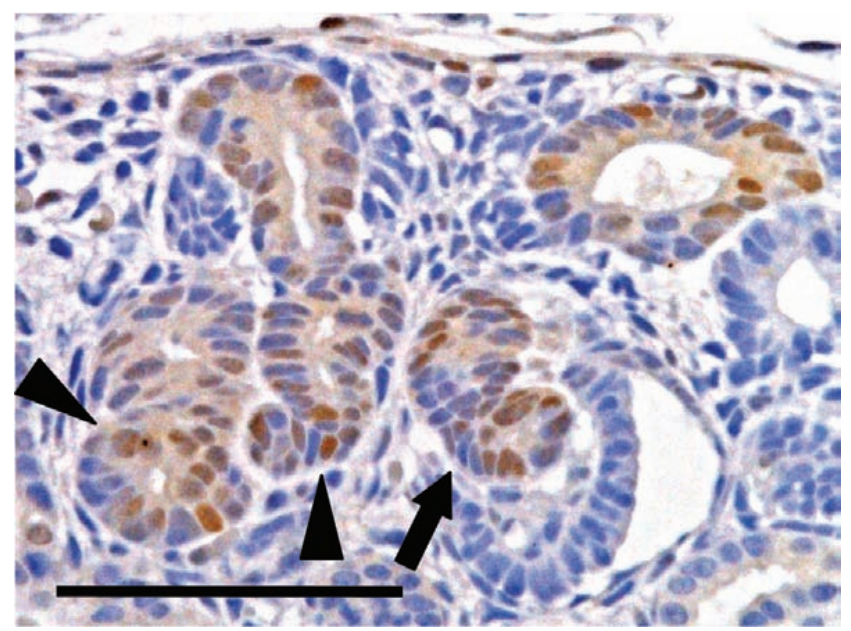

Fig. 5. 
bedded in paraffin; PLP solution-fixed specimens were embedded in paraffin by the AMeX method (PLP-AMeX method) ${ }^{10}$. Formalin-fixed, paraffin-embedded samples were cut at a thickness of 3-4 $\mu \mathrm{m}$, and stained with hematoxylineosin (HE) for morphology.

For immunohistochemistry, the specimens were cut at a thickness of 4- $\mu \mathrm{m}$, deparaffinized with xylene, rehydrated with graded ethanol and washed in water. These sections were boiled with microwave for 5 minutes for antigen retrieval. They were then treated with $3 \% \mathrm{H}_{2} \mathrm{O}_{2}$ for 10 minutes at room temperature for blocking of endogenous peroxidase. Tissue sections were incubated with polyclonal anti-COX-2 (1:300, Cayman Chemical Company.), polyclonal anti-mPGES-1 (1:200, Cayman Chemical Company.), polyclonal anti-EP4 (1:500, Upstate Biotechnology Inc.) and monoclonal anti-cyclin D1 (1:200, Upstate Biotechnology Inc.) for $12-14$ hours at $4{ }^{\circ} \mathrm{C}$. Thereafter, sections were washed three times with phosphate-buffered saline (PBS) and incubated for 45 minutes with the secondary antibody (Histofine Sample Stain MAX PO, Nichirei Corporation, Tokyo, Japan). Positive reactions were visualized with 3, 3'-diaminobenzidine (DAB). Sections were lightly counterstained with hematoxylin.

Rat nephrogenesis was described previously ${ }^{11}$. Briefly, in fetuses on GDs 18 and 21, loosely arranged blastemal cell-derived mesenchymal cells were abundantly observed among developing renal tubules and glomeruli in the cortical areas. The developing glomeruli consisted of round-, comma- and S-shaped bodies in lineage. The mesenchymal cells were gradually decreased with age after birth (neonates). Instead, maturing renal tubules and glomeruli became predominant in the cortex and medulla (Fig. 1). In the medullary areas of the fetuses on GDs 18 and 21, loosely arranged mesenchymal cells surrounding the branches of epithelial ureteric tubules were observed. In neonates on days $1-15$, the loosely arranged mesenchymal cells gradually decreased; in neonates on day 18, matured renal tubules and collecting ducts were developed, and a few mesenchymal cells were present in the tubulointerstitium in the medulla.

The immunoexpressions of COX-2 (Fig. 2A), mPGES-1 (Fig. 3), EP4 (Fig. 4) and cyclin D1 (Fig. 5) were observed in the developing tubules (Fig. 2A, 3, 4 and 5) in fetuses and early neonates. Except cyclin D1, which was expressed in both the nucleus and cytoplasm in the developing tubules (Fig. 5), the positive reactions for other antibodies were seen in the cytoplasm. As renal development proceeded, the expression patterns in the renal tubules were close to those of adult animals; COX-2 was restricted in the straight tubules in the cortex and macula densa (Fig. 2B); mPGES-1 was limited in the renal tubules in the medulla, which develop into the thin limb of the loop of Henle; cyclin D1 was seen only in the nuclei of renal tubular epithelial cells; EP4 was restricted in the distal tubules.

In the S-shaped body, immunoreactions for COX-2 (Fig. 2A), EP4 (Fig. 4) and cyclin D1 (Fig. 5) were observed, but that of mPGES-1 was not observed (Fig. 3 inset). In the interstitium, mesenchymal cells reacted to EP4 (Fig. 4) and cyclin D1 (Fig. 5) in varying degrees.

In metanephric development, mutual induction between the blastemal mesenchymal cells and epithelial cells of the ureteric bub occurs initially; after that, some blastemal cell-derived mesenchymal cells form epithelial cells of the renal tubules and glomeruli through mesenchymalepithelial transition in the cortex, whereas others persist in the interstitium and maintain the features of mesenchymal cells ${ }^{12}$. $\mathrm{PGE}_{2}$, which is synthesized from arachidonic acid converted by COX-1 or COX-2, has important roles in nephrogenesis and homeostasis in the kidneys ${ }^{1,2,13}$. However, COX-1 seems not to be essential for renal development because no alterations were observed in renal structures in COX-1 deficient mice ${ }^{14}$. On the contrary, COX-2 deficient mice exhibit abnormal renal development ${ }^{15,16}$. As demonstrated in this study, COX-2 expression was seen in the developing renal tubules in fetuses and early neonates, indicating participation of COX-2 in development of renal epithelial cells from blastemal cells in fetuses ${ }^{17}$. Moreover, we investigated the expression patterns of mPGES-1, a $\mathrm{PGE}_{2}$ biosynthesis-related enzyme, and EP4 in developing rat kidneys. In agreement with the expression of COX-2, mPGES-1 and EP4 were expressed in developing renal tubules of fetuses and early neonates. These findings indicate that $\mathrm{PGE}_{2}$ can regulate renal tubular epithelial development (in

Fig. 1. Histology of nephrogenesis in a neonate on day 1. Developing renal tubules (arrows) and maturing glomeruli (arrowhead) are present. HE stain. Bar $=100 \mu \mathrm{m}$.

Fig. 2. Immunohistochemical findings for cyclooxygenase (COX)-2 in fetuses on gestation days (GDs) 18 (A) and 21 (B). COX-2 expressions are observed in developing renal tubules (arrowhead) and S-shaped bodies (arrow, A) on GD 18 and in the macula densa (arrowhead) of juxtamedullary nephrons on GD 21 (B). Immunohistochemical staining, counterstained with hematoxylin. Bar=100 $\mu$ m.

Fig. 3. Immunohistochemical findings for microsomal $\mathrm{PGE}_{2}$ synthetase (mPGES)-1 in a neonate on day 1. Expressions of mPGES-1 are observed in the developing tubules (arrowheads), but not in S-shaped bodies (inset: Bar=20 $\mu$ m). Immunohistochemical staining, counterstained with hematoxylin. Bar $=100 \mu \mathrm{m}$.

Fig. 4. Immunohistochemical findings for $\mathrm{PGE}_{2}$ receptor (EP) 4 in a fetus on GD 18. EP4 expressions are observed in the developing renal tubules (arrowheads) and S-shaped bodies (arrow), as well as occasional interstitial mesenchymal cells. Immunohistochemical staining, counterstained with hematoxylin. Bar $=100 \mu \mathrm{m}$.

Fig. 5. Immunohistochemical findings for cyclin D1 in a neonate on day 1. Cyclin D1 expressions are observed in both the nucleus and cytoplasm of the developing renal tubule (arrowheads) and S-shaped bodies (arrow), as well as mesenchymal cells. Immunohistochemical staining, counterstained with hematoxylin. Bar $=100 \mu \mathrm{m}$. 
developing nephrons) via EP4 and that the $\mathrm{PGE}_{2}$ is induced mainly by COX-2. In the S-shaped body, the expressions of COX-2, EP4 and cyclin D1 were observed; however, that of mPGES-1 was not observed. Because PGES has multiple forms, namely mPGES-1, mPGES-2 and cPGES ${ }^{18}$, other forms of PGES might participate in glomerular formation from $\mathrm{S}$-shaped bodies. In addition to mesenchymal cells reacting to EP4 and cyclin D1, the significance of S-shaped body development remains to be pursued further.

Previously, we showed that COX-2 expression was decreased in the stage of renal tubule regeneration after CDDP injury 7 . This finding differed from the increased expression of COX-2 seen in developing renal tubules in the present study. Cyclin D1 is a marker of the $\mathrm{G}_{1}$ phase in the cell cycle $^{9}$; the expression is seen in the nucleus in cells at the $\mathrm{G}_{1}$ phase and the cytoplasm in cells at the $\mathrm{S}$ phase ${ }^{19}$. The epithelial cells in developing renal tubules showed a positive reaction to cyclin D1 in both the nucleus and cytoplasm, which is indicative of normal cell cycle regulation. Because the expressions of COX-2 and EP4 were also observed at the same site as cyclin D1 expression, COX-2 and its product, $\mathrm{PGE}_{2}$, are considered to be involved in normal proliferation and cellular differentiation of blastemal cell-derived renal tubules through EP4. On the other hand, cyclin D1 expression was restricted within the nucleus of regenerating renal epithelia in CDDP-treated kidneys, suggesting abnormal regeneration of the affected renal tubules?

In conclusion, it was found that endogenous $\mathrm{PGE}_{2}$ plays important roles in nephrogenesis, particularly blastemal cell-derived renal tubular development in the cortex, via EP4 expression. During development, COX-2 acted as an important inducer. Additionally, cyclin D1 expressions seen in the epithelial nucleus and cytoplasm indicated normal proliferation and cellular differentiation in the developing renal tubules. These findings were different from those of CDDP-induced renal lesions, which showed decreased COX-2 expression and exclusive nuclear expression of cyclin $\mathrm{D} 17,20$. We had expected that developing renal tubules might reflect epithelial regeneration of CDDP-injured renal tubules. The differences between developing renal tubules and CDDP-injured renal epithelia might give us some clues to pursue the pathogenesis of renal fibrosis after tissue injury.

Acknowledgments: This work was supported in part by a Grant-in-Aid (No. 22380173 to J Yamate) for Scientific Research B from the Japan Society for the Promotion of Science (JSPS).

\section{References}

1. Breyer MD, and Breyer RM. Prostaglandin E receptors and the kidney. Am J Physiol Renal Physiol. 279: F12-F23. 2000. [Medline]

2. Kotnik P, Nielsen J, Kwon TH, Krzisnik C, Frøkiaer J, and Nielsen S. Altered expression of COX-1, COX-2, and mPGES in rats with nephrogenic and central diabetes insipi- dus. Am J Physiol Renal Physiol. 288: F1053-F1068. 2005. [Medline] [CrossRef]

3. Kudo I, and Murakami M. Prostaglandin E synthase, a terminal enzyme for prostaglandin E2 biosynthesis. J Biochem Mol Biol. 38: 633-638. 2005. [Medline] [CrossRef]

4. Bondesen BA, Mills ST, Kegley KM, and Pavlath GK. The COX-2 pathway is essential during early stages of skeletal muscle regeneration. Am J Physiol Cell Physiol. 287: C475C483. 2004. [Medline] [CrossRef]

5. Harris RC, McKanna JA, Akai Y, Jacobson HR, Dubois $\mathrm{RN}$, and Breyer MD. Cyclooxygenase-2 is associated with the macula densa of rat kidney and increases with salt restriction. J Clin Invest. 94: 2504-2510. 1994. [Medline] [CrossRef]

6. Câmpean V, Theilig F, Paliege A, Breyer M, and Bachmann S. Key enzymes for renal prostaglandin synthesis: site-specific expression in rodent kidney (rat, mouse). Am J Physiol Renal Physiol. 285: F19-F32. 2003. [Medline]

7. Yamamoto E, Izawa T, Juniantito V, Kuwamura M, Sugiura $\mathrm{K}$, Takeuchi T, and Yamate J. Involvement of endogenous prostaglandin E2 in tubular epithelial regeneration through inhibition of apoptosis and epithelial-mesenchymal transition in cisplatin-induced rat renal lesions. Histol Histopathol. 25: 995-1007. 2010. [Medline]

8. Maeshima A, Yamashita S, and Nojima Y. Identification of renal progenitor-like tubular cells that participate in the regeneration processes of the kidney. J Am Soc Nephrol. 14: 3138-3146. 2003. [Medline] [CrossRef]

9. Massagué J. G1 cell-cycle control and cancer. Nature. 432: 298-306. 2004. [Medline] [CrossRef]

10. Suzuki M, Adachi K, Ogawa Y, Karasawa Y, Katsuyama K, Sugimoto T, and Doi K. The combination of fixation using PLP fixative and embedding in paraffin by the AMeX method is useful for immunohistochemical and enzyme histochemical studies of the lung. J Toxicol Pathol. 13: 109-113. 2000. [CrossRef]

11. Yuasa T, Izawa T, Kuwamura M, and Yamate J. Thy-1 expressing mesenchymal cells in rat nephrogenesis in correlation with cells immunoreactive for a-smooth muscle actin and vimentin. J Toxicol Pathol. 23: 1-10. 2010. [CrossRef]

12. Antonucci R, Cuzzolin L, Arceri A, and Fanos V. Urinary prostaglandin E2 in the newborn and infant. Prostaglandins Other Lipid Mediat. 84: 1-13. 2007. [Medline] [CrossRef]

13. Norwood VF, Morham SG, and Smithies O. Postnatal development and progression of renal dysplasia in cyclooxygenase-2 null mice. Kidney Int. 58: 2291-2300. 2000. [Medline] [CrossRef]

14. Langenbach R, Morham SG, Tiano HF, Loftin CD, Ghanayem BI, Chulada PC, Mahler JF, Lee CA, Goulding EH, Kluckman KD, Kim HS, and Smithies O. Prostaglandin synthase 1 gene disruption in mice reduces arachidonic acid-induced inflammation and indomethacin-induced gastric ulceration. Cell. 83: 483-492. 1995. [Medline] [CrossRef]

15. Dinchuk JE, Car BD, Focht RJ, Johnston JJ, Jaffee BD, Covington MB, Contel NR, Eng VM, Collins RJ, Czerniak PM, Stewart AG, and Trzaskos JM. Renal abnormalities and an altered inflammatory response in mice lacking cyclooxygenase II. Nature. 378: 406-409. 1995. [Medline] [CrossRef]

16. Morham SG, Langenbach R, Loftin CD, Tiano HF, Vouloumanos N, Jennette JC, Mahler JF, Kluckman KD, Ledford A, Lee CA, and Smithies O. Prostaglandin synthase 2 gene 
disruption causes severe renal pathology in the mouse. Cell. 83: 473-482. 1995. [Medline] [CrossRef]

17. Zhang MZ, Wang JL, Cheng HF, Harris RC, and McKanna JA. Cyclooxygenase-2 in rat nephron development. Am J Physiol. 273: F994-F1002. 1997. [Medline]

18. Kudo I, and Murakami M. Prostaglandin E synthase, a terminal enzyme for prostaglandin E2 biosynthesis. J Biochem Mol Biol. 38: 633-638. 2005. [Medline] [CrossRef]

19. Diehl JA, Cheng M, Roussel MF, and Sherr CJ. Glycogen synthase kinase-3beta regulates cyclin D1 proteolysis and subcellular localization. Genes Dev. 12: 3499-3511. 1998. [Medline] [CrossRef]

20. Yamamoto E, Izawa $T$, Juniantito V, Kuwamura $M$, and Yamate J. Relationship of cell proliferating marker expressions with PGE2 receptors in regenerating rat Renal tubules after cisplatin injection. J Toxicol Pathol. 23: 271-275. 2010. [CrossRef] 